\title{
Modelagem do Equilíbrio de Fases do Pentano e da Mistura de Pentano e $\mathrm{CO}_{2}$
}

\author{
Patrícia B. Gusmão, Leonardo Baptista \& Márcio Paredes
}

\section{Introdução}

A descrição precisa do comportamento de fases da mistura de hidrocarbonetos e dióxido de carbono não é apenas um problema acadêmico, mas também é fundamental em muitos campos industriais e tecnológicos, tais como a concepção de equipamentos de separação nas indústrias química e de energia, recuperação avançada de petróleo, e sistemas geotérmicos avançados com presença de $\mathrm{CO}_{2}$.

O sistema tem recebido maior atenção devido ao crescente interesse na captura e armazenamento geológico do dióxido de carbono. O equilíbrio de fases da mistura em questão desempenha um papel importante na avaliação do comportamento em longo prazo do dióxido de carbono em reservatórios subterrâneos profundos.

Este trabalho tem como objetivo investigar o equilíbrio de fases de hidrocarbonetos e da mistura de hidrocarbonetos e dióxido de carbono através de simulação molecular utilizando o método de Monte Carlo.

\section{Métodos}

$\mathrm{O}$ método de Monte Carlo (MC) foi utilizado para simular o equilíbrio de fases do pentano puro e da mistura binária de pentano e dióxido de carbono. As simulações foram realizadas nas temperaturas $343 \mathrm{k}, 350 \mathrm{k}, 400 \mathrm{k}, 410 \mathrm{k}$, $420 \mathrm{k}, 430 \mathrm{k}, 440 \mathrm{k}$ e $450 \mathrm{k}$, considerando um total de 1000 moléculas no sistema. Aplicou-se o campo de força Trappe em conjunto ao ensemble de Gibbs NVT. O programa utilizado foi o MCCCS Towhee'.

\section{Resultados e discussões}

Os resultados obtidos por simulação foram comparados com os valores estimados por interpolação nas curvas experimentais encontradas na literatura. ${ }^{2,3}$

Para as simulações com o pentano puro, o modelo demonstrou ser representativo na predição da entalpia de vaporização. Pode se observar que a curva simulada se aproxima da curva experimental à medida que a temperatura se aproxima da temperatura crítica do pentano, 469K. O maior desvio encontrado foi na temperatura de $343 \mathrm{k}$, que apresentou um erro próximo a $8 \%$; e o menor desvio encontrado foi na temperatura de $440 \mathrm{k}$, que apresentou um erro de $0,8 \%$. Os dados podem ser observados na Tabela e Figura 1. Os dados estimados por interpolação na curva experimental estão em vermelho. É possível observar pelos gráficos que o acordo entre os dados teóricos e experimentais aumenta a medida que a temperatura aumenta.

Tabela 1: Dados teóricos e experimentais de $\Delta \mathrm{H}$ (vap) do pentano. Resultados teóricos obtidos com o campo de força Trappe. Valores em $\mathrm{kJ} \mathrm{mol}^{-1}$.

\begin{tabular}{|c|c|c|c|}
\hline \multicolumn{4}{|c|}{ Entalpia de vaporização } \\
\hline & & \multicolumn{2}{c|}{ Dados simulados } \\
\hline Temperatura & Experimental & Teórico & Desvio padrão \\
\hline 310 & 25,5 & - & - \\
\hline 343 & 23,4 & 21,6 & 0,215 \\
\hline 350 & 23 & 21,2 & 0,222 \\
\hline 390 & 19,7 & - & - \\
\hline 400 & 18,6 & 17,3 & 0,176 \\
\hline 410 & 17,4 & 16,4 & 0,344 \\
\hline 420 & 16,3 & 15,2 & 0,315 \\
\hline 430 & 15,1 & 14,1 & 0,391 \\
\hline 440 & 12,9 & 12,8 & 0,468 \\
\hline 450 & 10,7 & 11,2 & 0,564 \\
\hline 460 & 8,5 & - & - \\
\hline
\end{tabular}




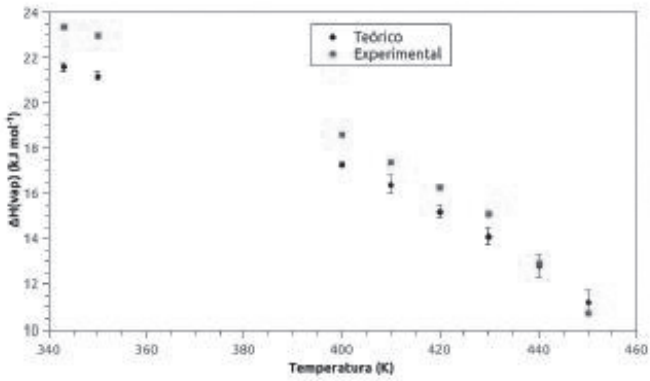

Figura 1: Comparação entre dados teóricos e dados experimentais.

Os valores teóricos para a densidade da fase líquida apresentam um bom acordo com os dados experimentais para o pentano puro, porém os desvios dos valores teóricos foram elevados, indicando que a simulação necessita ser refinada.

Todos as simulações anteriores negligenciaram o termo eletrostático do campo de força, visto que a molécula é apolar e não apresenta carga. Foi realizada uma simulação a $343 \mathrm{k}$ contabilizando o termo eletrostático, porém o mesmo não se mostrou vantajoso. $\mathrm{O}$ valor de entalpia de vaporização obtido foi similar ao calculado sem a contribuição eletrostática e com um desvio padrão menor, porém o tempo de simulação praticamente dobrou.

Outros campos de força também foram testados, entre eles o SKS. O equilíbrio de fases do pentano puro foi modelado também a 343K utilizando o campo de força SKS nas mesmas condições anteriores. $\mathrm{O}$ erro relativo observado neste campo de força foi de aproximadamente $9 \%$, próximo ao erro indicado pelo campo de força Trappe, que ficou em torno de $8 \%$. Os desvios observados foram baixos em ambos os campos de força.

Outras temperaturas precisam ser avaliadas para uma melhor análise. Os dados mencionados podem ser observados na Tabela 2.

Tabela 2. Comparação entre dados teóricos. Valores em kJ mol${ }^{-1}$.

\begin{tabular}{|c|c|c|c|c|c|c|}
\hline \multicolumn{7}{|c|}{$\Delta \mathrm{H}($ vap) $-343 \mathrm{~K}$} \\
\hline $\begin{array}{c}\text { Trappe colo } \\
\text { termo } \\
\text { eletrostático }\end{array}$ & $\begin{array}{c}\text { Desvio } \\
\text { pad. }\end{array}$ & $\begin{array}{c}\text { Trappe sem } \\
\text { termo } \\
\text { eletrostático }\end{array}$ & $\begin{array}{c}\text { Desvio } \\
\text { pad }\end{array}$ & SKS & $\begin{array}{c}\text { Desvio } \\
\text { pad. }\end{array}$ & \\
\hline 21,5 & 0,08 & 21,6 & 0,2 & 25,5 & 0,5 & 23,4 \\
\hline
\end{tabular}

Para as simulações com a mistura pentano e dióxido de carbono, o modelo demonstrou ser representativo na predição da fração molar dos componentes na fase vapor. Foram encontrados dados experimentais para fração molar em função da temperatura e pressão nas temperaturas de $408,15 \mathrm{~K}$ e $438,15 \mathrm{~K}$. Estes dados foram comparados com os dados teóricos obtidos a $410 \mathrm{~K}$ e $440 \mathrm{~K}$, assumindo que a diferença entre estes valores de temperaturas pode ser negligenciada. Pode-se observar uma boa aproximação entre os valores interpolados a partir dos dados experimentais e os valores obtidos por simulação. $\mathrm{O}$ erro em ambas as temperaturas foi menor que 2,5\%. Estes dados podem ser observados na Tabela 3.

Tabela 3. Dados experimentais e dados simulados da fração molar de $\mathrm{CO} 2$. Os dados em vermelho foram obtidos por extrapolação dos dados experimentais.

\begin{tabular}{|c|c|c|c|c|c|}
\hline \multicolumn{3}{|c|}{ Fraçao Molar 408.15k } & \multicolumn{3}{c|}{ Fraçao Molar 438. 15k } \\
\hline P kPa & Exp. & Simulaçao & P kPa & Exp. & Simulaçaq \\
\hline 1400 & 0.114 & - & - & - & - \\
\hline 1779 & 0.264 & - & 2206 & 0.113 & - \\
\hline 1908 & 0.299 & 0.305 & 2800 & 0.19 & 0.186 \\
\hline 2413 & 0.439 & - & 2820 & 0.193 & - \\
\hline
\end{tabular}

\section{Conclusão}

Os sistemas estudados via método de Monte Carlo no ensamble de Gibbs NVT demonstraram boa confiabilidade na predição das entalpias de vaporização do pentano e das frações molares na fase vapor da mistura de pentano e dióxido de carbono. Entretanto o modelo e a metodologia aplicada ainda precisam ser melhorados e aplicados a outros hidrocarbonetos e suas misturas com $\mathrm{CO}_{2}$, assim como o cálculo de outras propriedades termodinâmicas do sistema em equilíbrio, como densidade e pressão. A próxima etapa é simular o equilíbrio de fases para hidrocarbonetos de maior ordem e suas misturas com $\mathrm{CO}_{2}$.

\section{Agradecimento CAPES, CNPq e FAPERJ.}




\section{Referências}

1. http://towhee.sourceforge.net, acessado em 14/11/2015.

2. Leu, A. D.; Robinson, D. B. J. Chem. Eng. Data 1987, 32, 447-450.

3. http://webbook.nist.gov/cgi/cbook.cgi?ID=C109660\&Mask=4 \#Thermo-Phase, acessado em 14/11/2015.

\section{Patrícia B. Gusmão ${ }^{*}$, Leonardo Baptista² \& Márcio Paredes ${ }^{1}$}

\footnotetext{
${ }^{1}$ Universidade Estadual do Rio de Janeiro, Instituto de Química, Rio de Janeiro - RJ

${ }^{2}$ Universidade Estadual do Rio de Janeiro, Faculdade de Tecnologia, Resende - RJ

*pbgusmao@gmail.com
} 